\title{
PROJETO DE PESQUISA DE LIVRO DIGITAL PARA CRIANÇAS SURDAS E OUVINTES A LUZ DO DESIGN EM SITUAÇÕES DE ENSINO-APRENDIZAGEM
}

RESEARCH PROJECT FOR A DIGITAL BOOK FOR HEARING-IMPAIRED CHILDREN ON TEACHING-LEARNING SITUATIONS IN VIEW OF DESIGN

\author{
COUTO, Rita Maria de Souza \\ PUC-Rio \\ ricouto@puc-rio.br \\ PORTUGAL, Cristina \\ PUC-Rio \\ crisportugal@gmail.com \\ IUNG, Eliane Jordy \\ PUC-Rio \\ eliane.jordy@gmail.com \\ CORREIA, Ana Tereza \\ PUC-Rio \\ anacorreia@globo.com
}

Resumo: Visando discutir o potencial do Design inserido no campo da Educação, o artigo apresenta as bases metodológicas para o desenvolvimento de um livro interativo digital para crianças surdas e ouvintes. Experiência acumulada pela equipe do Laboratório Interdisciplinar de Design/Educação do Departamento de Artes \& Design da Pontifícia Universidade Católica do Rio de Janeiro (PUC-Rio) com o desenvolvimento em 2007 do projeto de pesquisa 'Multi-Trilhas: jogo para auxiliar a aquisição de segunda língua por crianças surdas'. A investigação, que tem um viés qualitativo, está sendo desenvolvida nos moldes de uma pesquisa exploratória, na forma de um estudo de caso. Para o desenvolvimento do livro digital serão usadas as contribuições de uma metodologia ágil, combinando Scrun e Kanban. A parceria celebrada entre o Instituto de Educação de Surdos e a instituição será de fundamental importância na medida em que propiciará o desenvolvimento de um trabalho conjunto, com validações e trocas de conhecimentos da equipe de pesquisa do Laboratório Interdisciplinar de Design/Educação da PUC-Rio com professores e fonoaudiólogos implicados em uma proposta de 
trabalho educativo orientado para as possibilidades da criança, além dos alunos do referido Instituto.

Palavras-chave: Design Educação, Design em Situações de Ensinoaprendizagem, Narrativa de historias, Linguagem Visual de Interface.

\begin{abstract}
In order to discuss the potential of Design within the field of Education, the article presents the methodological foundations for the development of a digital interactive book for hearing-impaired and hearing children. Experience accumulated by the Interdisciplinary Laboratory for Design/Education from the Department of Arts \& Design at PUC-Rio team in 2007, with the development of the research project 'Multi-Tracks: game to assist the acquisition of a second language by hearing-impaired children'. The investigation, which has a qualitative method, is being developed along the lines of an exploratory research in the form of a case study. For the development of the digital book, the contributions of an agile methodology, combining Scrun and Kanban, will be used. The partnership between a renowned institute specialized in education for the hearingimpaired and <hiden> will be extremely relevant. This will allow the development of a joint work, with validations and knowledge exchange between the Interdisciplinary Laboratory for Design/Education team and the teachers and speech therapists from the institute, which are involved in an educational work directed to the possibilities of children and the students of the Institute.
\end{abstract}

Keywords: Design Education, Design in Teaching/Learning situations, Storytelling, Interface Visual Language.

\title{
1. INTRODUÇÃO
}

Este artigo apresenta o processo do projeto de pesquisa, o qual foi contemplado pela Chamada Universal 14/2013 - $\mathrm{CNPq}^{1}$, que visa apresentar o potencial do Design inserido no campo da Educação e decorre da experiência da equipe do Laboratório Interdisciplinar de Design/Educação do Departamento de Artes \& Design da Pontifícia Universidade Católica do Rio de Janeiro (PUC-Rio) que iniciou um projeto de pesquisa coordenado pela professora Dra. Rita Couto intitulado 'MultiTrilhas: jogo para auxiliar a aquisição de segunda língua por crianças surdas'. Esse projeto, realizado entre os anos de 2004 a 2007, teve por público crianças surdas matriculadas no ensino fundamental do Instituto Nacional de Educação de Surdos do Rio de Janeiro - INES/RJ. Com clara abordagem interdisciplinar, recebeu uma bolsa "Cientistas de Nosso Estado" da FAPERJ (2005-2007) e bolsa de Produtividade em Pesquisa do CNPq (2006-2009). Por intermédio desta última, foi realizado um

\footnotetext{
${ }^{1}$ Processo: $472713 / 2013-2$
} 
desdobramento do jogo Multi-Trilhas, com a preparação e disponibilização no site www.multi-trilhas.com da versão multimídia do referido jogo ${ }^{2}$.

A iniciativa de atuação no sentido coletivo, ao reunir diferentes visões, saberes e experiências advindas da pesquisa - e também do contato com professores, alunos e pedagogos do INES/RJ - representa um desdobramento natural e uma marca registrada dos trabalhos desenvolvidos no laboratório. Neste estudo, pretende-se reunir investigações sobre as diversas relações do Design em Situações de Ensinoaprendizagem referente ao desenvolvimento de sistemas de hipermídia, sua aplicabilidade, técnicas e métodos à luz do Design e a interação de sua práxis com a Educação e a sociedade na qual ele se insere. Como produto aplicado da presente pesquisa pretende-se desenvolver um material didático hipermidiático, em formato de livro de história paradidático, destinado preferencialmente, mas não exclusivamente, a crianças surdas, a ser elaborado em conjunto com pedagogos e professores implicados em uma proposta de Educação inclusiva.

Nesse sentido, a presente proposta de pesquisa, por meio de revisão bibliográfica, leitura e análise crítica de textos, tem por foco estudos sobre materiais didáticos inovadores que possam gerar experiências significativas no processo de ensino-aprendizagem de crianças surdas com o auxílio de ambientes hipermidiáticos.

\section{FUNDAMENTAÇÃO TEÓRICA}

Como atividade multidisciplinar, o Design trabalha com várias áreas de conhecimento, permitindo uma visão abrangente no desenvolvimento de projetos que solucionem problemas diversos e atendam as mais variadas necessidades. Dessa forma, como atividade de múltiplas abordagens, o Design atua com diversas ênfases tendo a intenção de maximizar os objetivos do projeto.

Nas palavras de Bonsiepe (2011), os conhecimentos considerados como experiências acumuladas devem ser comunicados e compartilhados, sendo que a apresentação da informação/conhecimento deveria ser uma tarefa central do Design. Essa ideia se coaduna com os objetivos da proposta de pesquisa, que reúne as áreas de Design de Hipermídia e Educação, com foco em estudos sobre a interatividade e a experiência do usuário.

Para Moura (2003), o Design de Hipermídia exige que o designer domine não apenas a relação imagem e texto, mas também, a gramática advinda de outras linguagens, como por exemplo, a imagem dinâmica ou em movimento, o som e suas relações, as questões de organização e estruturação das informações, as questões relativas à interatividade, mobilidade, navegabilidade, e também os elementos para concepção e composição da interface.

Ainda segundo as palavras de Moura (2003), a interação possibilitada pelas tecnologias digitais ampliaram quatro qualidades do ser humano:

"[...] apesar da agilidade na mudança de sistemas e processos, podemos perceber que as tecnologias digitais exteriorizaram e impulsionaram quatro qualidades do ser humano: a curiosidade, a criatividade, a cooperação e a vivência do lúdico.

\footnotetext{
${ }^{2}$ A equipe do LIDE foi entrevistada sobre este projeto em rede de televisão no canal 2 - TV Brasil, no programa especial, no dia 6 de abril de 2013.
} 
Sendo a interatividade apontada como uma das melhores aberturas para estas questões e para o pensamento criador." (MOURA, 2003: 206).

Nesta mesma linha, Ruberti e Pontes (2001), ao considerar os significativos avanços das tecnologias de informação e comunicação, preconizam que a escola de nosso tempo compete o árduo trabalho de incorporar em suas práticas e teorias novas formas de ensino-aprendizagem, voltadas para a potencialização de competências para o uso de múltiplas linguagens que convergem em ambientes de hipermídia. (RUBERTI E PONTES, 2001, p. 03).

A pertinência da pesquisa que está sendo proposta pode ser justificada a partir de dois polos. No primeiro, tomando-se as palavras de Bonsiepe (1997), a interação entre o usuário e o produto é o Design. Assim, acredita-se que seja promissor um trabalho conjunto entre essa área e a Educação, com foco na experiência do usuário, com fins educacionais, para potencializar as competências necessárias ao uso de múltiplas linguagens, promovendo uma melhoria nos padrões da Educação e tornando o aprendizado mais produtivo e interativo.

O segundo polo diz respeito ao significativo crescimento do interesse pela área da surdez, principalmente entre pesquisadores linguistas, educadores, psicólogos, entre outros, visto que este tema constitui um campo fértil para discussões. A presente pesquisa traz o designer para este universo de investigação e sua participação se dá por meio de instrumentos próprios a seu campo de expertise: o projeto de um material educativo que tem por objetivo auxiliar crianças surdas no processo inicial de aquisição do Português escrito como segunda língua, no âmbito do ensino fundamental, do $1^{\circ}$ ao $4^{\circ}$ ano, através de uma abordagem interdisciplinar, com foco no Design.

A deficiência não é um atributo da pessoa, mas um conjunto complexo de condições, muitas das quais criadas pelo meio ambiente social. Consequentemente, a solução do problema requer ação social e é de responsabilidade coletiva da sociedade fazer as modificações necessárias para a participação plena de pessoas com deficiências em todas as áreas da vida social. A questão é, pois, de atitude ou ideologia, quanto às mudanças sociais, enquanto que no nível político é uma questão de direitos humanos. (WHO, ICIDH - 2, 1998).

Diante dessa situação, torna-se fundamental desenvolver meios que possibilitem relações entre o conhecimento sobre as necessidades e potencialidades de crianças portadoras de necessidades especiais e os instrumentos, equipamentos e/ou brinquedos que podem estimular seu desenvolvimento e, consequentemente, facilitar sua inclusão na sociedade. Podemos considerar que essa abordagem é necessariamente dupla. Isto é, se por um lado é fundamental conhecer as necessidades e restrições, por outro lado, é também essencial pesquisar e encontrar os elementos que permitam resolver o problema, sendo a carência de modelos uma das principais lacunas a ser preenchida na maioria das escolas.

Nesse sentido, o trabalho de um designer no âmbito da Educação é, em grande parte, tido como uma atividade de projeto, no mesmo patamar daquela que leva à configuração de mapas, cartazes, livros, etc. Essa visão, um tanto quanto restritiva, requer a ampliação do raio de aplicação do material educativo, para que possamos 
entendê-lo como qualquer tipo de suporte que abrigue uma mensagem direcionada a um determinado tipo de aprendizagem.

Este desenvolvimento e a consequente inclusão mais igualitária, na sociedade, de crianças com necessidade especiais requer uma ideia de educação como algo que somente realiza sua função primordial se considera o sujeito como um ser autônomo apto a utilizar a palavra e o pensamento de forma eficiente - pois, a palavra é um fator essencial no desenvolvimento do pensamento, na evolução e na transformação do pensamento com um todo, como considera Vigotski (1987). As pessoas dialogam umas com as outras mediadas pela linguagem, seja ela verbal, gestual e visual. Essa ideia pode ser reforçada com as palavras do educador Paulo Freire (1986), quando ele diz que:

\footnotetext{
"Somente na comunicação tem sentido a vida humana. Que o pensar do educador somente ganha autenticidade na autenticidade do pensar dos educandos, mediatizados ambos pela realidade, portanto, na intercomunicação. Por isto, 0 pensar daquele não pode ser um pensar para este nem a este imposto." (Paulo Freire, 1986) ${ }^{3}$.
}

Sobre a essencialidade da linguagem na sociedade Kristeva diz que "se $a$ linguagem é a matéria do pensamento, é também o próprio elemento da comunicação social. Não há sociedade sem linguagem, tal como não há sociedade sem comunicação" (KRISTEVA, 1969, p. 18).

A alfabetização é um processo que transcende o fato de levar o aluno a verbalizar fonemas, palavras e frases e escrevê-las de forma isolada e mecanicamente. Alfabetizar é oferecer os recursos necessários para a criança utilizar o código de leitura e escrita como um instrumento eficaz de interação e, sobretudo, de comunicação com seu meio social. Assim, torna-se importante que o professor conceba a própria situação de aprendizagem como uma experiência que, se percebida e compreendida, possa fornecer fundamentos para que se reflita sobre a melhor maneira de ensinar 0 surdo a ler e a escrever.

A complexidade de conexão entre a LIBRAS e o Português é um desafio em projetos de educação bilíngue, já que - apesar de ser uma língua própria - na LIBRAS os verbos não são conjugados, nem são utilizadas preposições ou conectivos, dificultando o processo de alfabetização do Português como forma escrita da língua em relação à LIBRAS, como língua falada.

O que se percebe, segundo Maria Regina Luchesi (2003) é que a maneira como se realiza o processo de socialização dos surdos não lhes permitem construir outras realidades, diferentes das que Ihes são apresentadas, reafirmando, dessa forma, a sua condição de excluídos, ou de incluídos desigualmente.

Tendo como pressuposto que atividades com surdos não podem se limitar a um trabalho de mera aquisição de linguagem, neste estudo teremos por meta uma visão multissensorial, ou seja, enfatizaremos funções pelas quais o surdo recebe a impressão de objetos externos como, por exemplo, a visão e o tato. Visando atingir esses parâmetros, o livro digital disponibilizará para a criança surda uma variedade de possibilidades de relacionamento com a linguagem escrita e a LIBRAS, contribuindo

\footnotetext{
${ }^{3}$ FREIRE, Paulo. Pedagogia da Autonomia. São Paulo: Paz e Terra, 1996.
} 
para o desenvolvimento científico e tecnológico das áreas de conhecimento do Design e da Educação, com foco na Educação Especial.

A criação de um livro digital para crianças surdas, que trabalhe com a Língua Brasileira de Sinais - LIBRAS, em versão ilustrada e animada, constitui-se em uma inovação, considerando que a LIBRAS é predominantemente visuo-espacial.

Como resultados o projeto apresentará a produção de uma pesquisa teórica aliada às bases conceituais para o desenvolvimento de ambientes hipermidiáticos. Além disso, pretende-se disponibilizar um livro interativo para tablets, ou similares, onde a narrativa se dará por meio das múltiplas linguagens que se convergem em ambientes de hipermídia. O que se pretende é que ao usar o livro interativo - e acessar os conteúdos didáticos apresentados - a criança potencialize o seu processo de aprendizagem desenvolvendo habilidades e competências em diversas áreas do saber.

\section{JUSTIFICATIVA DO PROJETO}

Em que pese o fato de muitos estudos sobre hipermídia já terem sido desenvolvidos, ainda há carência de pesquisas que determinem diretrizes para uma linha de trabalho conjunto do Design com outras áreas do conhecimento, como é o caso da Educação, visando à construção de ambientes de hipermídia, abrindo uma nova forma de conceber e produzir design.

Podemos considerar que ainda há certa carência de critérios para o desenvolvimento e utilização de tecnologias digitais contemporâneas no ensino e a consequência direta dessa carência é uma distância expressiva entre o ensino regular em escolas e as possibilidades de ensino-aprendizagem disponibilizadas pelas novas mídias. Fato que se torna mais agravante no ensino e na formação em design, uma vez que cabe a um designer ser um tradutor de signos e linguagens estando, portanto, preparado para entender e atuar com as tecnologias contemporâneas, presentes e disseminadas pelos sistemas e linguagens digitais relacionadas à informação e a comunicação. Sob essa perspectiva, pesquisas como a que está sendo aqui proposta, podem contribuir para desenhar metodologias, fundamentar ações e aplicar resultados de estudos realizados, revertendo positivamente para os processos de ensino-aprendizagem de Design que tem lugar na universidade.

Para Portugal (2013), não existem teorias e modelos educacionais que possam ser diretamente utilizados e nenhuma ferramenta tecnológica que disponibilize de forma direta materiais educacionais. Geralmente, não há, também, integração adequada dos campos que são fundamentais para esse trabalho. Citamos como exemplo, as tecnologias de hipertexto, multimídia, redes e ferramentas para trabalho cooperativo que exigem um novo design e uma nova, ou outra forma, de se relacionar que privilegie a aquisição das competências e habilidades necessárias para a busca, seleção das informações, e construção do conhecimento nos ambientes educacionais disponíveis ou a serem projetados.

Os sistemas de informação estão hoje inseridos em um ambiente de permanente desafio, que requer atualização e desenvolvimento de novas formas de apresentação, para além das tradicionais - associando gráficos, tipografia, movimento, som e interatividade e tornando-se compreensível e utilizável pelas pessoas. Com isso, torna- 
se fundamental buscar novos modelos, métodos e abordagens para 0 desenvolvimento de sistemas de hipermídia para a Educação que possam disponibilizar informações significativas criando experiências agradáveis no processo de ensino-aprendizagem.

Identificamos, por exemplo, que uma das dificuldades relatadas por professores do INES/RJ é a falta de concentração das crianças, e a carência de recursos que as motive a prestar atenção no professor. A criança que tem a possibilidade de interação com o suporte/objeto/recurso disponível tende a ter mais foco, pois é parte integrante daquele processo. Chegamos a essa conclusão em testes realizados com a observação direta do objeto em uso no Multi-Trilhas Virtual. Participando, a criança se concentra na atividade e seu ganho em relação a aprendizagem é maior.

\section{METODOLOGIA DA PESQUISA}

A presente investigação, que tem um viés qualitativo, está sendo desenvolvida nos moldes de uma pesquisa exploratória, na forma de um estudo de caso, em consonância com outras fontes que darão base ao tema abordado, como pesquisa bibliográfica e documental, leitura e análise crítica de textos, entrevistas com alunos e professores que farão parte das experiências práticas, entre outras técnicas.

Para o desenvolvimento do livro digital serão usadas as contribuições de uma metodologia ágil, combinando Scrun e Kanban ${ }^{4}$. A metodologia do Scrun, geralmente é usada para uma gestão dinâmica de projetos, sendo muitas vezes uma prática relacionada com o desenvolvimento ágil de um software. A metodologia do Kanban está relacionada à utilização de cartões (post-it e outros) para indicar o andamento dos fluxos de desenvolvimento de projetos. Atualmente, o Kanban é muitas vezes usado em conjunto com o Scrum, porque são duas metodologias que podem promover melhor transparência do andamento do projeto em desenvolvimento, de modo a contribuir para a motivação e o maior comprometimento da equipe, favorecendo a inspeção contínua e proporcionando maior facilidade de alterações durante o desenvolvimento do projeto (figura 1). A seguir encontra-se apresentado o processo de pesquisa.

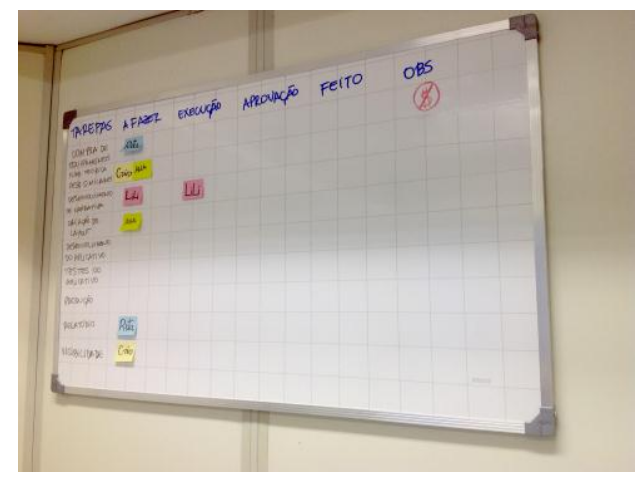

Figura 1 - Quadro do processo da metodologia do Kanban. Elaborado pelo autor, com base na pesquisa realizada.

\footnotetext{
${ }^{4}$ Signficados.com. Disponível em: http://www.significados.com.br/kanban/, Acesso em 05 Jan. 2014.
} 


\section{Processo de pesquisa}

1a Etapa: Pesquisa bibliográfica e pesquisa documental.

Realizar levantamento de fontes para definir o referencial teórico que sustentará os fundamentos de conceitos teóricos e estéticos de Design em ambientes digitais.

Investigar as relações do Design em Situações de Ensino-aprendizagem referente ao desenvolvimento de sistemas de hipermídia, tendo como foco o estudo sobre as tecnologias digitais contemporâneas no ensino e a experiência do usuário visando auxiliar a propagação e o aprofundamento desta área de conhecimento.

Planejar e desenvolver a metodologia para aplicação das entrevistas e sessões de observação no Instituto de Educação de Surdos.

2a Etapa: Pesquisa bibliográfica e pesquisa documental; leitura e análise crítica de textos.

Identificar possibilidades de interação dos recursos de Design nos projetos de hipermídia, analisar e identificar o valor de cada um deles no auxílio a motivação, aspectos lúdicos e imersão.

Investigar questões que envolvem sistemas digitais, tais como interatividade; visualização de dados complexos em ambientes digitais; plataformas de software e hardware de baixo custo e abertos (open source); computação pervasiva e ubíqua; construção de narrativas em mídias digitais; e os impactos da tecnologia digital na sociedade contemporânea.

Investigar como métodos e técnicas de Design e sua aplicabilidade em sistemas digitais podem colaborar para o processo de ensino-aprendizagem, consequentemente, facilitar a construção do conhecimento.

Analisar os resultados com o objetivo de reforçar, exemplificar, fundamentar conhecimentos teóricos e práticos sobre o uso das tecnologias digitais contemporâneas no ensino com foco em questões relacionadas à experiência do usuário surdo.

3a Etapa: Pesquisa bibliográfica, leitura e análise crítica de textos.

Realizar a análise crítica do material investigado na primeira e na segunda etapa da pesquisa.

Discutir questões sobre a forma de apresentação de informação de maneira não linear, como hipertexto, em estrutura de nós semânticos ligados entre si (em rede), que ofereçam alternativas para a navegação e interação.

Discutir questões de como projetar para obter experiências significativas. Entender a experiência real, os agentes envolvidos e a relação entre os agentes.

Buscar conhecimentos básicos sobre recursos disponibilizados pelas novas tecnologias digitais contemporâneas aplicadas em ambientes hipermidiáticos educacionais. 
Relacionar conhecimentos teóricos e práticos sobre técnicas, materiais, suportes etc. para a elaboração de sistemas de hipermídia com foco na experiência do usuário no processo de ensino-aprendizagem.

4a Etapa: Análise crítica e síntese de textos.

Fornecer estratégias, à luz de metodologias de design, para a construção de ambientes hipermidiáticos educacionais visando desenvolvimento tecnológico e inovação para o ensino em Design.

Criar diretrizes a luz do Design em Situações de Ensino-aprendizagem para o desenvolvimento de interfaces digitais que possa colaborar para o processo de ensino-aprendizagem que visem desenvolver o raciocínio lógico; possibilite que o usuário lide com os próprios erros de forma produtiva; estimule a curiosidade (exploração do novo); possibilite o desenvolvimento da imaginação/criatividade; colabore para que o usuário tome decisões, escolhas mais rápidas, fortaleça a autonomia; e que ofereça ritmos diferentes de leitura e de resposta.

5a Etapa: Entrevistas.

Realizar entrevistas semiestruturadas com grupo de alunos do INES, e de outras instituições, professores e profissionais da área de Design, a partir das observações feitas sobre o uso do livro digital. Os resultados serão analisados para reforçar, exemplificar e fundamentar a questão da experiência da criança no processo de ensino-aprendizagem.

6a Etapa: Projeto e validação do livro digital

Aplicar a metodologia Scrun e Kanban para gerenciamento do projeto de desenvolvimento do sistema.

Desenvolver livro digital para plataforma Apple - IPAD e similares, sob a perspectiva de metodologias do campo do Design e em parceria com profissionais do Instituto de Educação de Surdos, e de outras instituições interessadas.

Validar livro digital junto a professores, pedagogos e alunos do INES-RJ, e de outras instituições interessadas. Validar livro digital junto a professores, pedagogos e alunos (elaboração de roteiro de validação e referencial de análise).

Em que pese a apresentação em etapas, o processo de pesquisa será pautado por ações realizadas concomitantemente (figura 2). 


\section{PROCESSO METODOLÓGICO}
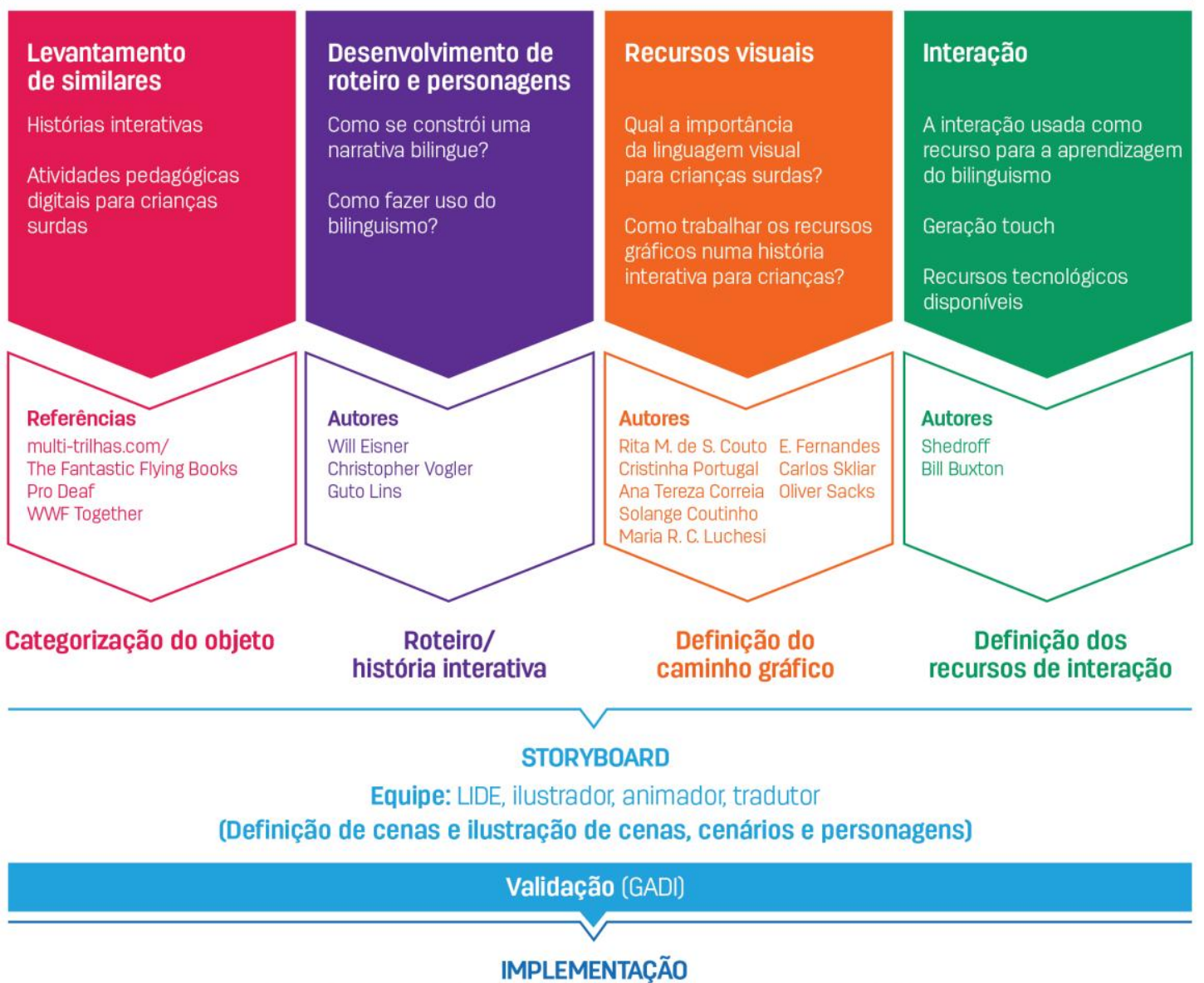

Equipe: LIDE, ilustrador, animador, tradutor e desenvolvedor

(Desenvolvimento de software, animação das cenas e personagens, implementação de recursos tecnológicos de interação, usabilidade e acessibilidade - geração de protótipo)

Validação (Av.Heurística + Instrumento de Avaliação Focado no Planejamento)

\section{VALIDAÇÃO}

Equipe: LIDE + instituição de ensino de surdos

(Teste para análise do protótipo com o público-alvo)

Validação (Observação Direta do Objeto em Uso)

AVALIAÇÃo
Equipe: LIDE
(Conclusão)

Figura 2 - Processo metodológico da pesquisa. Elaborado pelo autor, com base na pesquisa realizada.

\section{CONSIDERAÇÕES FINAIS}

Entre os resultados esperados para esta pesquisa encontra-se a de aprofundar a linha de pesquisa Design em Situações de Ensino-aprendizagem por intermédio do desenvolvimento de um ambiente digital interativo para crianças surdas, mas não exclusivamente, que reúna as principais reflexões realizadas no processo de 
investigação, disponibilizando para o campo acadêmico, e sociedade em geral, um sistema para inovação do ensino de crianças surdas.

Outra contribuição da pesquisa é a criação de diretrizes, a luz do Design em Situações de Ensino-aprendizagem, para o desenvolvimento de interfaces digitais no processo de ensino-aprendizagem e, ainda, cooperar com o desempenho científico e tecnológico do Estado do Rio de Janeiro.

Este projeto visa disponibilizar conceitos teóricos e estéticos para o desenvolvimento de ambientes hipermidiáticos em suportes como tablets, dentre outros com intuito de trazer inovação tecnológica para o processo educacional de crianças surdas, mas não exclusivamente para elas.

Como resultados o projeto apresentará a produção de uma pesquisa teórica aliada às bases conceituais para o desenvolvimento de ambientes hipermidiáticos. Além disso, pretende-se disponibilizar um livro interativo para tablets, ou similares, onde a narrativa se dará por meio das múltiplas linguagens que convergem em ambientes de hipermídia. O que se pretende é que ao usar o livro interativo - e acessar os conteúdos didáticos apresentados - a criança com surdez desenvolva habilidades e competências em diversas áreas do saber, possibilitando que suas especificidades sejam compreendidas e o seu processo de aprendizagem possa acontecer sem deslizes - visando, de fato, a sua inclusão na vida social.

O fortalecimento da parceria anteriormente celebrada entre o Instituto de Educação de Surdos e a PUC-Rio ainda em vigor, será de fundamental importância na medida em que propiciará o desenvolvimento de um trabalho conjunto, com validações e trocas de conhecimentos da equipe de pesquisa do LIDE com professores e fonoaudiólogos implicados em uma proposta de trabalho educativo orientado para as possibilidades da criança, além dos alunos do referido Instituto.

\section{REFERÊNCIAS}

BONSIEPE, G. Design, cultura e sociedade. São Paulo: Edgar Blucher, 2011.

CANCLINI, N. G. Culturas híbridas. 3a ed. São Paulo, Ed. da USP, 2000.

COUTO, R. M. S. Desenvolvimento de ilustrações de movimentos da Língua de Sinais Brasileira - LIBRAS". In: 4을 Congresso Internacional de Design da Informação \& 3우 InfoDesign Brasil | Congresso Brasileiro de Design da Informação, Rio de Janeiro: PUC-Rio, 2009.

CORREIA, A. T. P. S.; COUTO, R. M. S.; PORTUGAL, C. Multi-Trilhas Virtual: avaliação do jogo de entretenimento para a aquisição da linguagem por crianças surdas. In: P\&D

Design 2012. São Luíz: UFMA, 2012.

FERNANDES, E. Linguagem e Surdez. São Paulo: Artmed. 2003.

FERNANDEZ, S. M. A educação do deficiente auditivo: um espaço dialógico de produção de conhecimentos. Dissertação de Mestrado. Rio de Janeiro. UERJ, 1993.

FREIRE, P. Pedagogia da Autonomia. São Paulo: Paz e Terra, 1996.

INES. Anais do II Encontro de Alfabetização de Deficientes Auditivos. Rio de Janeiro. CIMART, 1988. 
KRISTEVA, Julia. História da Linguagem. Tradução Maria Margarida Barahona. Edições 70 - Lisboa, Portugal: Colecção Signos, 1969.

LOPES, M. C. A mediação material e sígnica no processo de integração de crianças surdas. In: SKLIAR, Carlos (org.) Educação e Exclusão - abordagens sócioantropológicas em educação especial. 3a ed. Porto Alegre: Mediação, 1997. p. 81-105.

LUCHESI, M.R. C. Educação de Pessoas Surdas. Campinas. Papirus, 2003.

MINISTÉRIO DA EDUCAÇÃO. Parâmetros Curriculares Nacionais: ensino médio: bases legais. Ministério da Educação/Secretaria de Educação Média e Tecnológica. Brasília, 1999.

MOURA. M. C. O Design de hipermídia. Tese (Doutorado). Programa de Pós Graduação em Comunicação e Semiótica. PUC/SP, São Paulo, 2003.

PORTUGAL, C. Design, Educação, Tecnologia. Rio de Janeiro: Rio Books, 2013.

PORTUGAL, C.; COUTO, R. M. S.; JORDY, E. ; CORREIA, A.; CORREA, M. F. G.. Proposta de livro interativo digital para crianças surdas. In: IV Simpósio de Pós-Graduação em Design (SPPG Design 2013), 2013, Bauru/SP. Anais do IV Simpósio de Pós-Graduação em Design (SPPG Design 2013). Bauru/SP, 2013.

SACKS, Oliver W. Vendo Vozes: uma viagem ao mundo dos surdos. São Paulo. Companhia das Letras: 1998.

SHEDROFF, N. Information interaction Design: a unified field theory of Design. Disponível em: <http://www.nathan.com/thoughts/unified/>. Acesso em: 05 fev. 2010.

SKLIAR, C. (Org.) Educação \& Exclusão. Abordagens Sócio-antropológicas em Educação Especial. 3ạ ed. Porto Alegre: Mediação. 1997.

VIGOTSKI, Lev. S. Pensamento e Linguagem. São Paulo: Martins Fontes. 1987.

WORLD HEALTH ORGANIZATION (WHO). Disponível em: < http://www.who.int/en/>. (WHO, ICIDH - 2, 1998). Acesso em 2004. 